\title{
Supplement of \\ Brief communication: Supraglacial debris-cover changes in the Caucasus Mountains
}

Levan G. Tielidze et al.

Correspondence to: Levan G. Tielidze (levan.tielidze@tsu.ge)

Table S1. Satellite images used in this study.

\begin{tabular}{|r|r|r|r|r|r|}
\hline Date & $\begin{array}{r}\text { UTM } \\
\text { zone }\end{array}$ & Type of imagery & Region/Section & Resolution & Scene ID \\
\hline $10 / 08 / 1985$ & $37 \mathrm{~N}$ & Landsat 5 & Western Greater Caucasus & $30 \mathrm{~m}$ & LT51720301985222XXX04 \\
\hline $06 / 08 / 1986$ & $38 \mathrm{~N}$ & Landsat 5 & Central Greater Caucasus & $30 \mathrm{~m}$ & LT51710301986218XXX02 \\
\hline $31 / 08 / 1986$ & $38 \mathrm{~N}$ & Landsat 5 & Eastern Greater Caucasus & $30 \mathrm{~m}$ & LT51700301986243XXX03 \\
\hline $12 / 09 / 2000$ & $37 \mathrm{~N}$ & Landsat 7 ETM+ & Western Greater Caucasus & $15 / 30 \mathrm{~m}$ & LE71720302000256SGS00 \\
\hline $05 / 09 / 2000$ & $38 \mathrm{~N}$ & Landsat 7 ETM+ & Central Greater Caucasus & $15 / 30 \mathrm{~m}$ & LE71710302000249SGS00 \\
\hline $28 / 07 / 2000$ & $38 \mathrm{~N}$ & Landsat 7 ETM+ & Eastern Greater Caucasus & $15 / 30 \mathrm{~m}$ & LE17003020000728SGS00 \\
\hline $23 / 08 / 2013$ & $37 \mathrm{~N}$ & Landsat 8 & Western Greater Caucasus & $15 / 30 \mathrm{~m}$ & LC81720302013235LGN00 \\
\hline $03 / 08 / 2014$ & $38 \mathrm{~N}$ & Landsat 8 & Central Greater Caucasus & $15 / 30 \mathrm{~m}$ & LC81710302014215LGN00 \\
\hline $28 / 08 / 2014$ & $38 \mathrm{~N}$ & Landsat 8 & Eastern Greater Caucasus & $15 / 30 \mathrm{~m}$ & LC81700302014240LGN00 \\
\hline $20 / 08 / 2016$ & $37 \mathrm{~N}$ & SPOT-7 & Elbrus & $1.5 \mathrm{~m}$ & DS_SPOT7201608200751063 \\
\hline
\end{tabular}

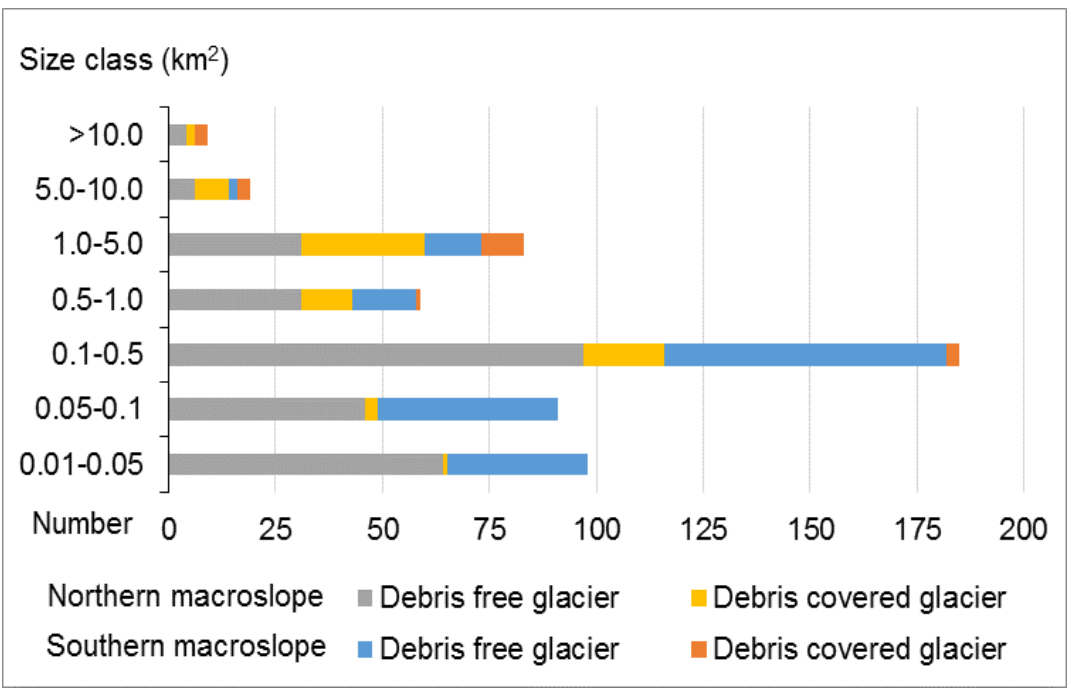

15 Figure S1. The Greater Caucasus glacier size classes with debris covered and debris free glaciers distributions for northern and southern slopes. 


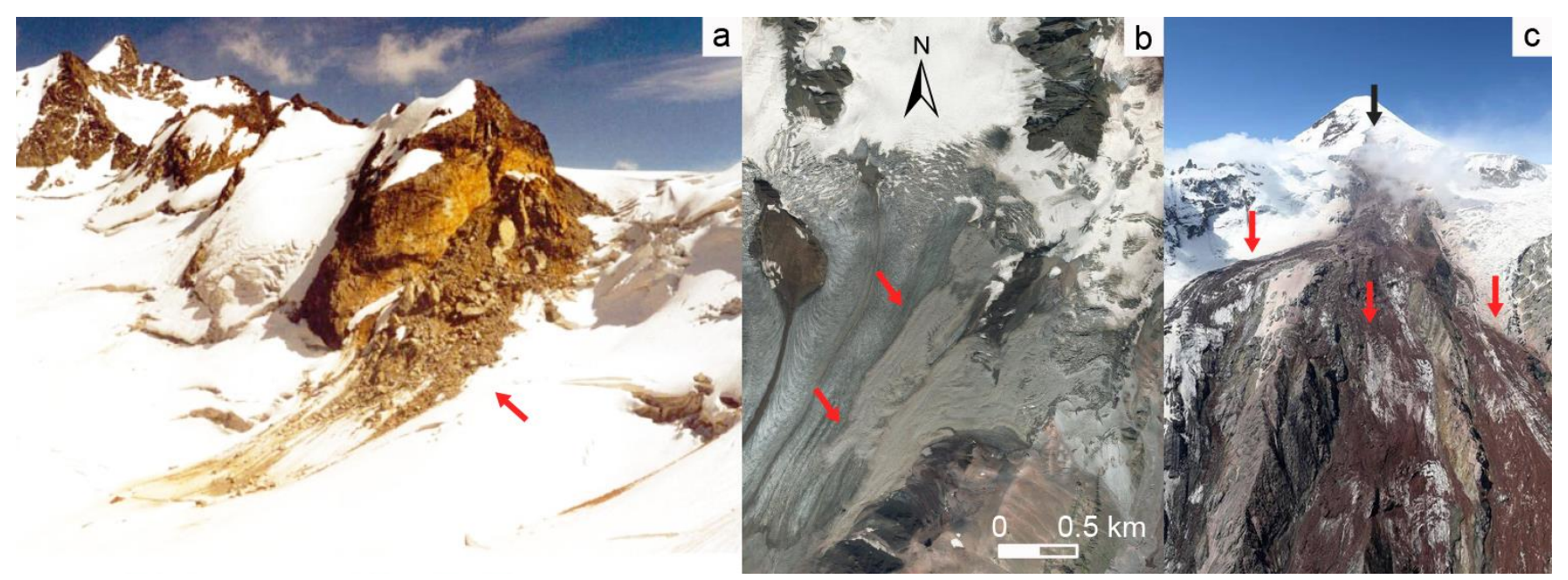

$5 \quad$ Figure S2. a - Djankuat (2001), b - Suatisi (2007, 2010), and c - Devdoraki (2014) glacier rock falls. Red arrows show the flow of the rock-ice avalanche. The black arrow shows the center of genesis of the rock-ice avalanche (4600 m asl).

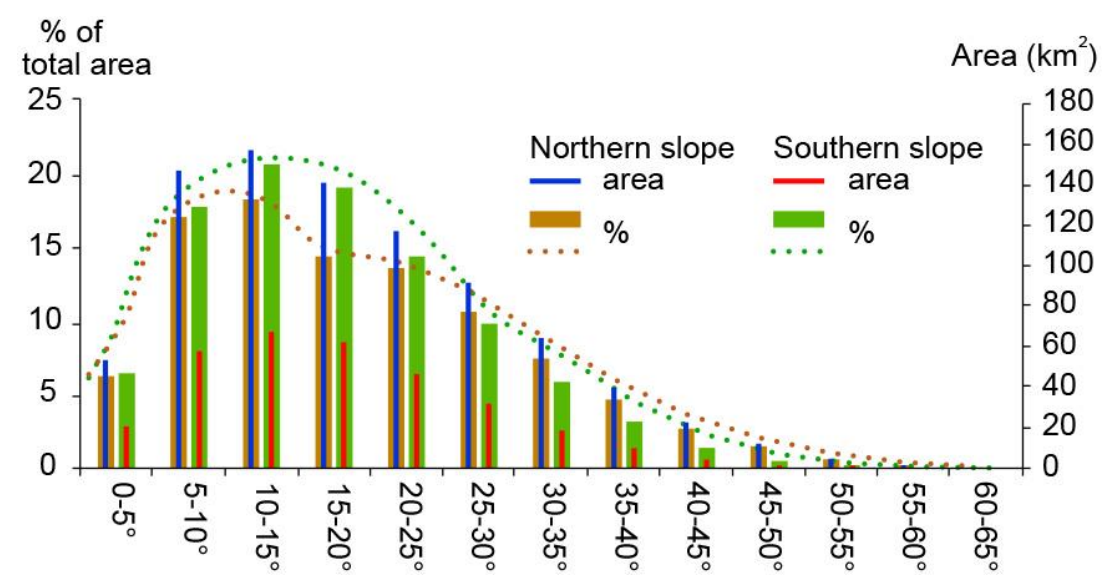

20 Figure S3. Greater Caucasus total glacier surface inclination for northern and southern slopes based on ASTER GDEM. 

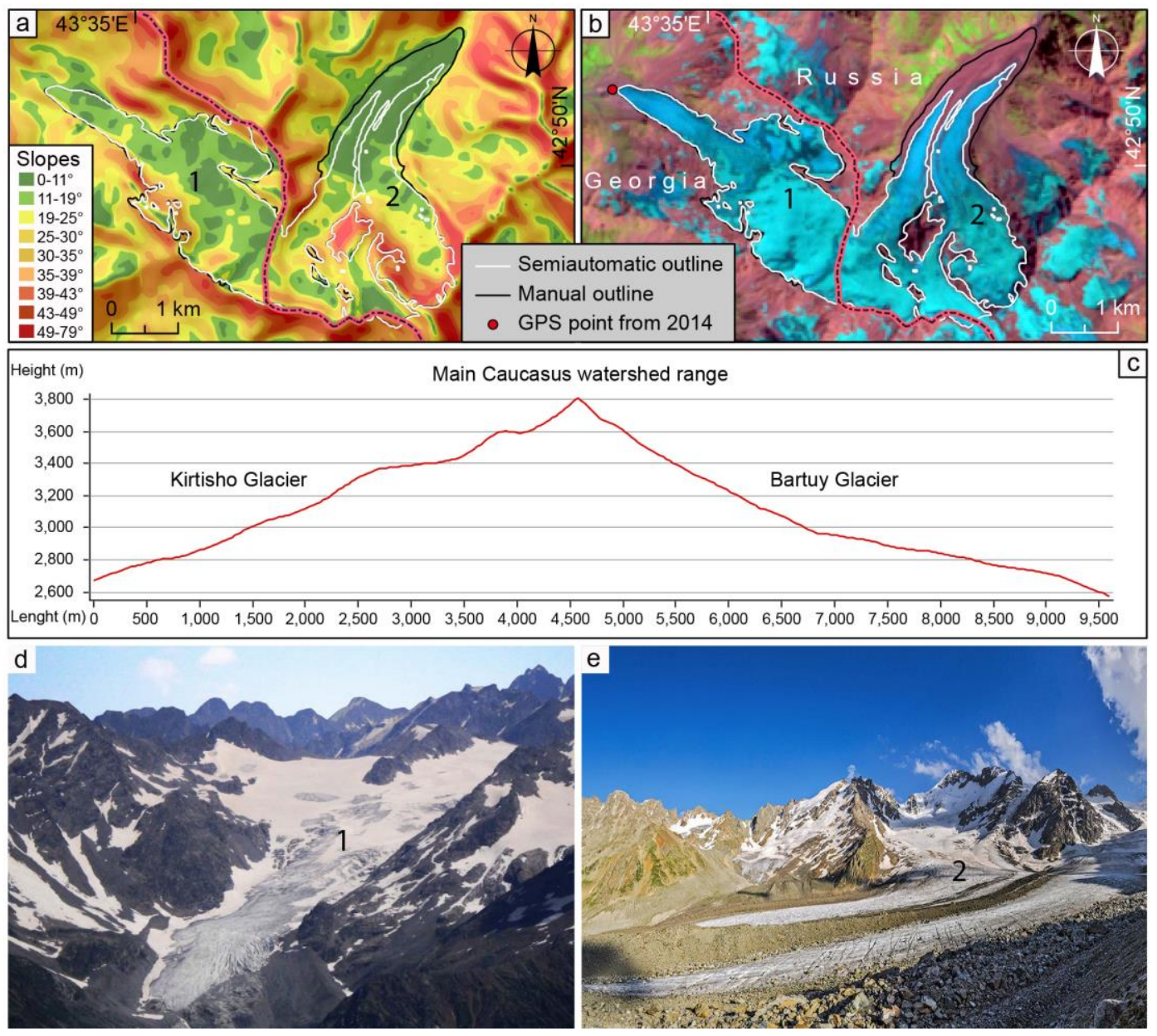

5 Figure S4. a1 - Kirtisho and a2 - Bartuy glaciers slope inclination map based on ASTER GDEM; (b) the manual and semi-automated outlines comparison and SDC assessment, Landsat 8 (3/08/2014); c - Kirtisho and Bartuy glaciers longitudinal profile based on ASTER GDEM; d - Kirtisho Glacier in 2010 (photo by L.G. Tielidze); e Bartuy Glacier in 2014 (photo by M. Golubev). 


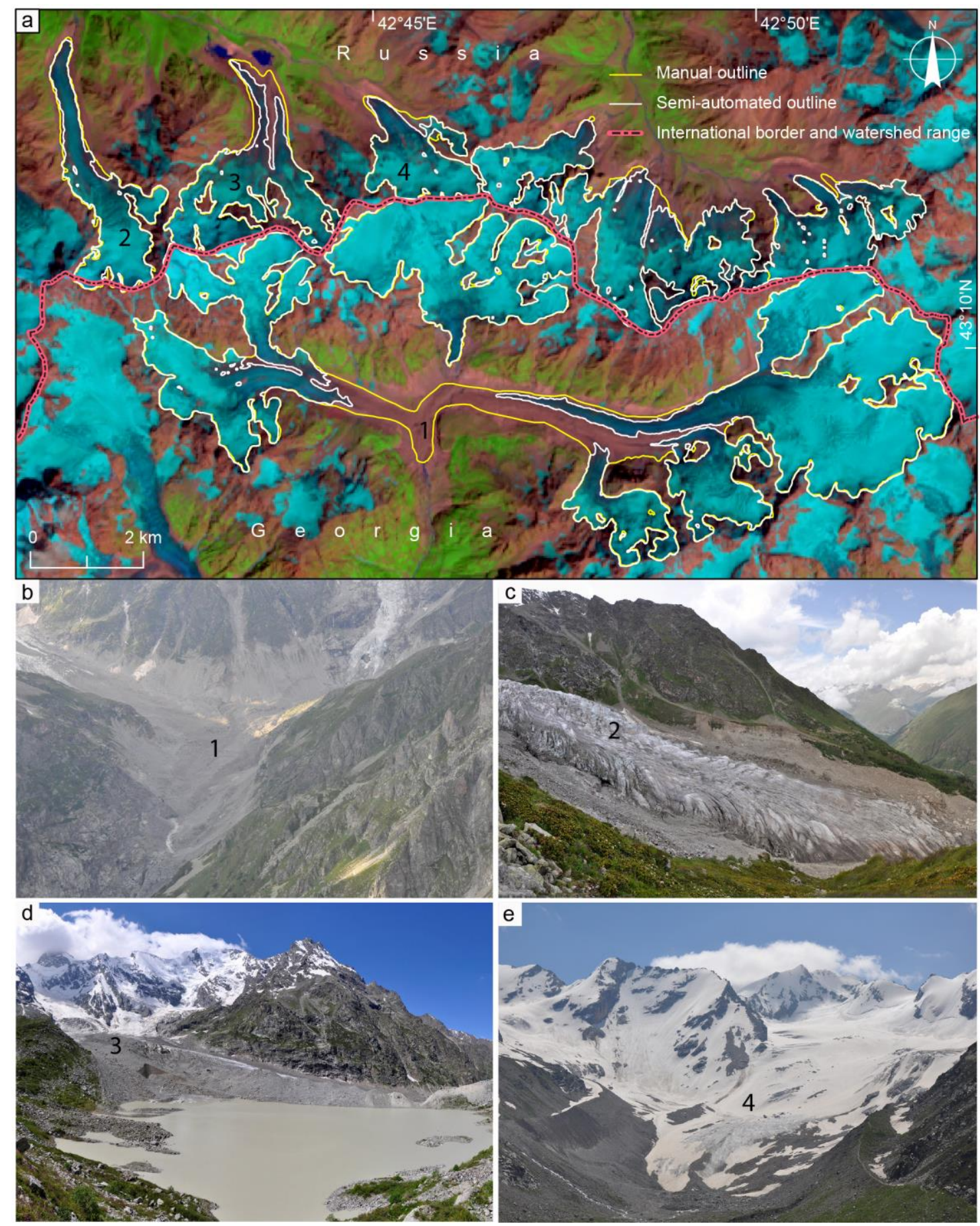

$5 \quad$ Figure S5. a - Manual and semi-automatic outlines comparison and SDC assessment for the southern (Lekhziri, a1) and northern (Kashkatash a2, Bashkara a3 and Djankuat a4 glaciers (Landsat 8 OLI 03/08/2014); b - Lekhziri Glacier tongue in 2011; c - Kashkatash Glacier tongue in 2014; d - Bashkara Glacier tongue in 2014; (e) Djankuat Glacier in 2014. 


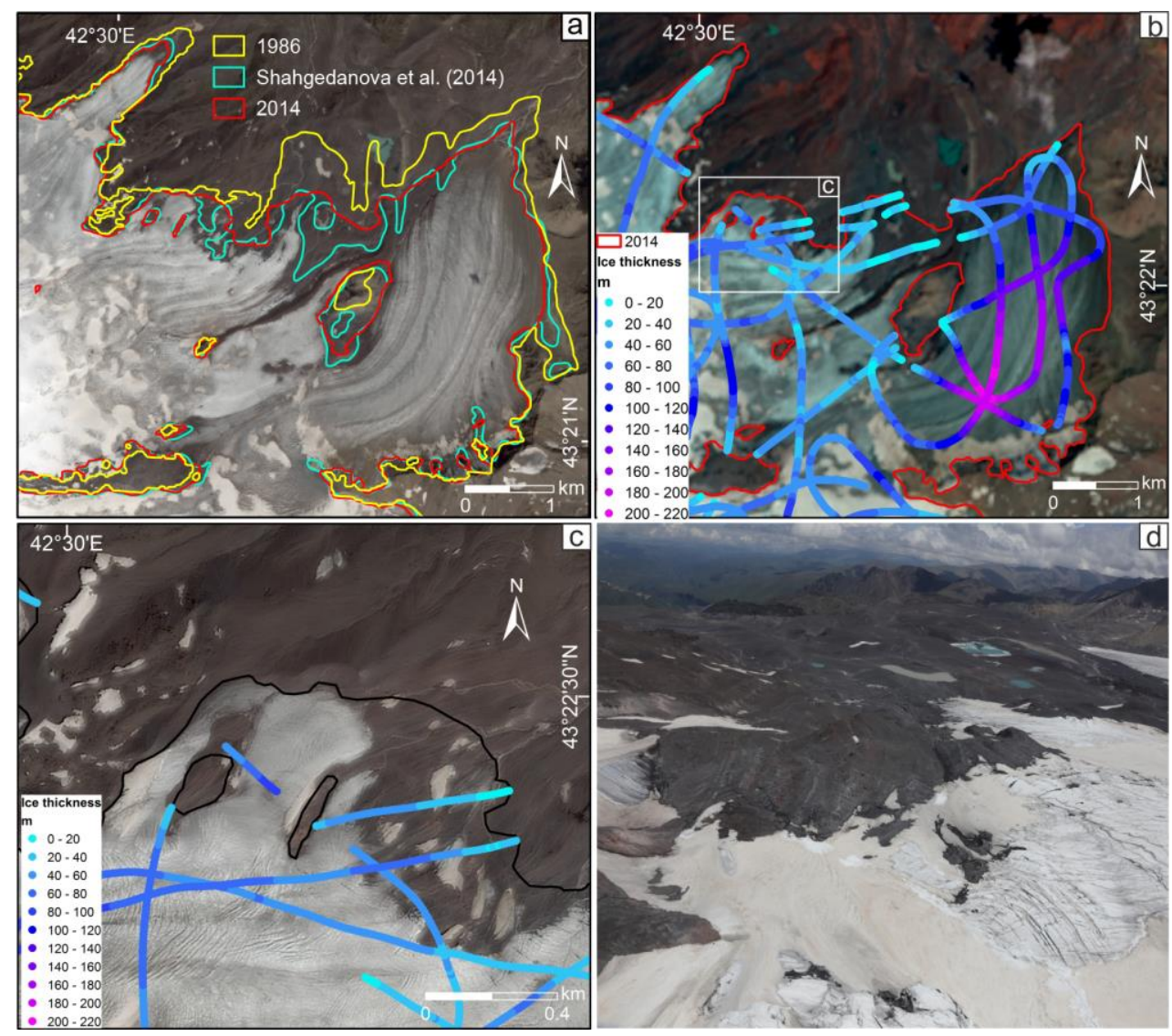

Figure S6. Glaciers of the eastern slope of Elbrus. a - glacier outlines of 1986 and 2014. Red outline shows glacier margins after GPR measurement. SPOT-7 image used as a background; b - Ice thickness profiles obtained during aerial GPR survey in 2014, Landsat 8 image of 2014; c - glacier outlines and ice thickness 5 profiles with SPOT-7 high resolution image; $\mathrm{d}$ - oblique photograph of the glacier tongues taken from helicopter in 2014.
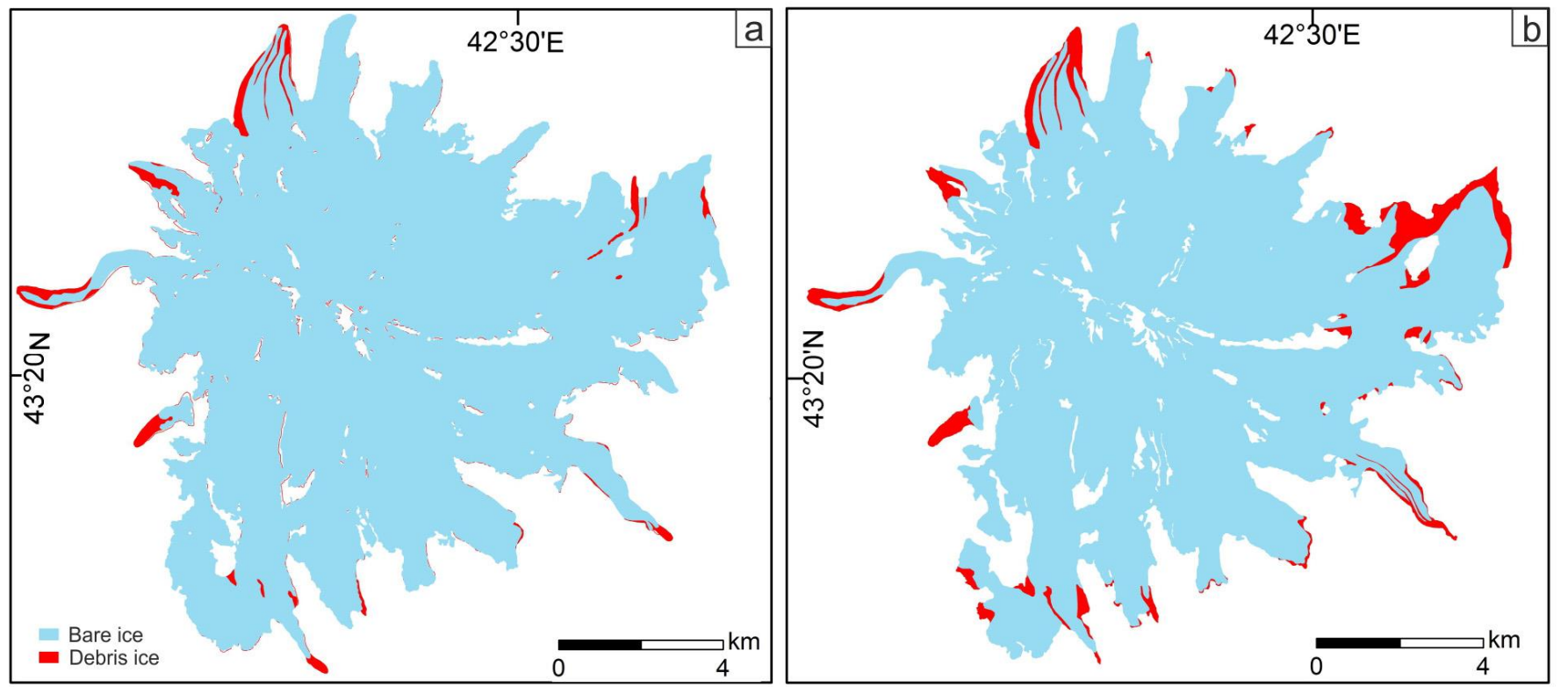

Figure S7. Debris cover increase on the Elbrus massif from 1986 (a) to 2014 (b). 

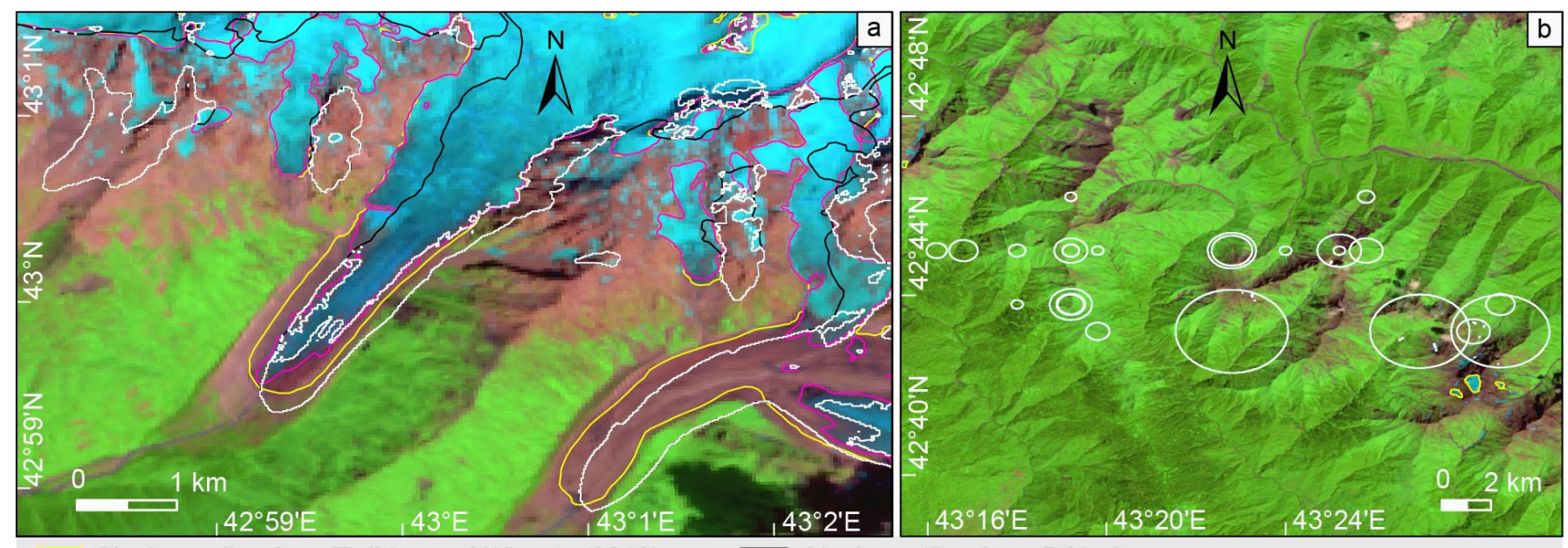

Glacier outline from Tielidze and Wheate (2018)

Glacier outline from RGI v6

Bare ice outline derived during this study

Debris cover outline from Scherler, et al. (2018)

Figure S8. a - An example of the RGI v6 data inconsistent registration; b - An example of the RGI v6 nominal 5 glaciers (circles). Landsat 8 image 03/08/2014 is used as the background. 